\title{
Soil Carbon density and Aggregates Stability under Three Types' Plantation Trees on Weibei Dryland, China
}

\author{
Lili Dong ${ }^{1}$ and meng kou ${ }^{1}$ \\ ${ }^{1}$ Xianyang Normal University
}

April 28, 2020

\begin{abstract}
Afforestation has been implemented on a large scale in the Loess Plateau of China since 1999. This paper aimed to judge the influence of plantation tree types on soil aggregate stability and carbon stocks. The results showed that : (1)the content of soil organic matter and macro-aggregates, the water stability of aggregates were significantly higher in P. tabuliformis plantation compared with R. pseudoacacia and M. pumila plantations, conversely, the content of soil calcium carbonate in P. tabuliformis plantation was the lowest; (2) the content of soil organic matter and organic carbon density were significantly negatively correlated with soil depth, while soil carbonate calcium and in-organic carbon density fluctuated with the increasing of soil depth; (3) compared with topsoil, subsoil was important carbon sink because there were more in-organic carbon; (4) Aggregate organic carbon increased while inorganic carbon decreased with the increasing of aggregate size respectively. We concluded that: (1) R. pseudoacacia played a more important role in soil carbon sequestration compared with P. tabuliformis; while P. tabuliformis was more beneficial to improve soil organic matter and soil structure; (2) subsoil and in-organic carbon were important carbon sinks compared with topsoil and organic carbon; (3) the bigger water stable aggregates having the higher content of soil organic matter and the lower carbonate calcium.
\end{abstract}

\section{Soil Carbon density and Aggregates Stability underThree Types'Plantation Trees on Weibei Dryland, China}

DONG Lili*, KOU Meng

College of resources, environment, history and culture, Xianyang Normal University, Xianyang, Shaanxi, 712000 , China

Abstract: Afforestation has been implemented on a large scale in the Loess Plateau of China since 1999. This paper aimed to judge the influence of plantation tree types on soil aggregate stability and carbon density. The results showed that: (1)the content of soil organic matter and macro-aggregates, the water stability of aggregates were significantly higher in $P$. tabuliformis plantation compared with $R$. pseudoacacia and $M$. pumila plantations, conversely, the content of soil calcium carbonate in P. tabuliformis plantation was the lowest; (2) the content of soil organic matter and organic carbon density were significantly negatively correlated with soil depth, while soil carbonate calcium and in-organic carbon density fluctuated with the increasing of soil depth; (3) compared with topsoil, subsoil was important carbon sink because there were more in-organic carbon; (4) Aggregate organic carbon increased while inorganic carbon decreased with the increasing of aggregate size respectively. We concluded that: (1)R. pseudoacacia played a more important role in soil carbon sequestration compared with $P$. tabuliformis; while P. tabuliformis was more beneficial to improve soil organic matter and soil structure; (2) subsoil and in-organic carbon were important carbon sinks compared with topsoil and organic carbon; (3) the bigger water stable aggregates having the higher content of soil organic matter and the lower carbonate calcium. 
Key words: Carbon density; Soil organic carbon; Soil inorganic carbon;Soil aggregate stability; Calcareous soils;Afforestation

\section{Introduction}

As a feasible option, forest ecosystems should not only alleviate water and soil erosion but also enhance soil carbon storage capacity, which can compensate for $\mathrm{C}$ loss through soil mineralization and burning fossil fuels. With the implementation of "Grain for Green" project, the area of plantation trees in China has reached to 61.68 million hectares, coming the first in the world. In the study area, in order to accommodate degradation of soils, arid and cold climate, exotic speciesRobinia pseudoacacia, which is fast growing and aid N-fixation, has been introduced for a long time; and native species Pinus tabulaeformis was often chosen as predominant reproducing tree species. Meanwhile, Malus pumila was also planted widely by local farmers in order to seek higher economic profits than others (such as Triticum aestivum and Zea mays ). Each plant species provides a different quality and quantity of organic material into soils, causing changes of soil properties (Mataix-Solera et al., 2007). For example, Bhattacharya et al.(2016) showed tree species significantly changed soil properties through roots and litters. Zhang et al.(2018a) concluded that $P$. tabulaeformis plantation greatly improved soil physical-chemical properties and biological activities. However Liu et al.(2012) found that broadleaved forests can most obviously improve soil quality, followed by broadleaved coniferous mixture and coniferous plantations. Chen et al. found the age-related fine root biomass (2016) and C:N:P stoichiometry (2018) were significantly different between $P$. tabulaeformis and $R$. pseudoacacia on the Loess Plateau. Mataix-Solera et al.(2007) concluded that compared with other species, Pinus halepensis should be planted in afforestation projects in semi-arid areas, because this species could produce more hydrophobic substances into the soil than other species. In addition, Nie et al.(2017) found plant species had no significant impact on soil organic carbon concentration. Cao et al.(2018a) also found that the differences of soil nutrients between black locust and Chinese pine were not obvious.

Afforestation has been seen as an important role to reduce soil erosion and improve soil quality, which is usually expressed by the content of soil organic carbon (SOC) or soil organic matter (SOM). Many parameters including bulk density and aggregate stability correlated well with SOC or SOM. Thereinto, aggregate stability, indicating soil structural stability, is often considered as an important soil quality (Zethof et al., 2019). In addition to, aggregate size distribution and stability can also be used to indicating of soil degradation (Boix-Fayos et al., 2001). Several processes affecting soil aggregate stability, such as breakdown of soil aggregates and the increase of soil bulk density, will accelerate the natural erosion rate of soil. Mean weight diameter (MWD) of water stable aggregates are recognized as an important indicator on the capability of the soil to resist against water erosional forces. It was believed that the SOC content played an important role in the soil aggregation (Nie et al., 2017). Meanwhile, stable aggregate played an important role in the stabilization of SOC (Qiao et al., 2016). It is generally accepted that the stability of SOC in soil aggregates due to the protection of aggregate structure from microbial decomposition (Qiao et al., 2016).

The focus of afforestation changed towards carbon stability in the last decades (Zhang et al., 2018b). Among the numerous sources of greenhouse gases, emissions of $\mathrm{CO}_{2}$ are affected by changes of land use (Bhattacharya et al., 2016). And the net changes in current land use patterns are expected to contribute to about $1.1 \pm 0.8$ Pg C year ${ }^{-1}$ to the atmosphere (Bhattacharya et al.,2016). Soil carbon consists of soil organic carbon (SOC) and soil inorganic carbon (SIC) (Zhang et al.,2018b, Yang et al.,2018). Determining changes in soil organic carbon (SOC) and inorganic carbon (SIC) stocks caused by forest planting is important for estimating the regional carbon budget and evaluating ecological effects (Han et al.,2018). The choice of tree species plays an important role in SOC accumulation. The Populusplantations were main carbon sink in forest vegetation with a carbon sequestration rate of $9.50 \mathrm{t} \mathrm{C/} \mathrm{(ha \cdot yr)} \mathrm{in} \mathrm{Beijing} \mathrm{(Xiao} \mathrm{et} \mathrm{al.,2011).} \mathrm{Li} \mathrm{and} \mathrm{Liu} \mathrm{(2014)} \mathrm{believed}$ that soil was a great reservoir for $\mathrm{C}$ storage in black locust plantations. The quantitative contribution of familiar plantation types to $\mathrm{C}$ sequestration is much debated. For example, Cao et al. (2018b) found that the SOC densities of the N-fixing black locust plantations were significantly lower than those of the Chinese pine plantations and secondary oak forests. However, Wang et al.(2010) found that after 23 years' growth, N-fixing species performed better in restoring soil $\mathrm{C}$ and $\mathrm{N}$ pools and their cycling. Tong et al.(2016) concluded that 
the total soil C stock in a depth of $100 \mathrm{~cm}$ was in the order: Robinia pseudoacacia $>$ Populus tomentosa $>$ Caragana korshinskii $=$ Hippophae rhamnoides , and $\mathrm{C}$ increased by 7.9 to $18.2 \mathrm{Mg} \mathrm{C}$ ha ${ }^{-1}$ compared with the arable land in the Loess Hill region of China.

In a word, even though some researches focused on the effect of forest plantations on aggregate stability, soil organic matter and carbon stocks. But firstly, few studies have focused on the relationship between SOC and SIC (Zhang et al.,2018b). Secondly, the majority of studies payed close attention to the surface soil and the attention given to deep soil was not enough (Zhang et al., 2018a, Chen et al.,2018).Thirdly, little attention has been paid to SIC, in spite of its relative abundance in the arid and semi-arid regions (Yang et al.,2018). Fourthly, some disagreements of the relationship between SOC or SOM and soil aggregate sizes have been reported:(1) SOC accumulation in macroaggregates (Du et al., 2013; Shu et al., 2015); (2) organic carbon mainly stored in small aggregates (Xie et al.,2015); (3)SOC in farmland tended to be concentrated in smallersized aggregates, whereas SOC under other land uses tended to concentrated in larger-sized aggregates(Liu et al.,2014). Finally, the studies concerning aggregate stability applied different initial diameter, such as $<19 \mathrm{~mm}$ (Briedis et al.,2012), $<8 \mathrm{~mm}$ (Chai et al.,2019), 2-4 and 4-8 $\mathrm{mm}$ (Thomaz, 2017), 4.75-8 and $<4.75$ mm(Ahmadi et al.,2011), which led to difficult comparisons among them. Therefore, Quantifying Carbon storage, SOM and aggregate stability in R. pseudoacacia, P. tabuliformis and M. pumila plantations will contribute to tree species selection in afforestation as carbon sink increase, water and soil conservation measures. Especially, when soil organic carbon and inorganic carbon are all considered at soil profiles under semi-arid climate conditions.

The objectives of this study were to (1) study the effect of plantation types on soil structural stability and soil carbon density, (2) analyze the influence of the initial diameter on mean weight diameter of water stable aggregates, (3) test the validity of the aggregate hierarchy theory.

\section{Materials and Methods}

\section{1 study area and soil sampling}

Study area was located in the Liquan county, which is the middle region of Shaanxi Province, China. The mean annual temperature is 12.6 with the highest monthly temperature in July (34) and the lowest in January(-4) and with 214 frost-free days. The mean precipitation is $517.6 \mathrm{~mm}$. The studied soil is calcareous. Soil samples were taken in Malus pumila, Robinia pseudoacacia and Pinus tabuliformis plantations. The mean diameter at breast height (DBH) of $R$. pseudoacacia , P. tabuliformis and $M$. pumila is $15.42,12.73$ and 12.98 $\mathrm{cm}$ respectively. The average $\mathrm{pH}$ of surface soil under the site of $R$. pseudoacacia, P. tabuliformis and $M$. pumila is 8.33, 7.97 and 8.42 respectively. During September, under the sample sites of $R$. pseudoacacia, $P$. tabuliformis and M. pumila, soil profiles were dig into $80 \mathrm{~cm}$ and $50 \mathrm{~cm}$ (intervals of $10 \mathrm{~cm}$ ) using a spade respectively. Soil samples were air-dried for one-week and stored at room temperature.

\subsection{Experimental design}

In order to obtain dry aggregate samples with different diameter, firstly, soil samples were separated by moving a cascade of sieves with openings of $10,7,5,2,1.2 \mathrm{~mm}$ for $10 \mathrm{~min}$. Secondly, the aggregates were put into an oven at 40 for $24 \mathrm{~h}$ so that they had a constant matric potential. Thirdly, $5-10 \mathrm{~g}$ subsample of dry aggregate with different diameter was gently submerged into distilled water for 30 minutes, then washed onto a $0.05 \mathrm{~mm}$ sieve and into $200 \mathrm{~mL}$ beakers using ethyl alcohol successively, and separated by moving a cascade of sieves with openings of $5,2,1,0.5,0.2,0.1 \mathrm{~mm}$ after drying at 40 and weighed. The treatment was replicated three times.

SOM concentrations of the aggregate fractions and the bulk samples were determined using the oil bath$\mathrm{K}_{2} \mathrm{Cr}_{2} \mathrm{O}_{7}$ titration method. The content of in-organic carbon was determined by volume of carbon dioxide from reaction with hydrochloric acid. Bulk density was measured with a standard technique using a cutting ring with $50 \mathrm{~cm}^{3}$ volume driven vertically downward into the midrange of each horizon.

\subsection{Data analysis}


Mean weight diameter (MWD) was calculated using the following formula. Where $\overline{x_{i}}$ (in millimetre) is a mean diameter of two consecutive sieves, and $\mathrm{w}_{\mathrm{i}}$ is corresponding mass percent.

$M W D=\frac{\sum_{i=1}^{n} \overline{x_{i}} w_{i}}{\sum_{i=1}^{n} w_{i}}(1)$

Soil organic carbon density(hereafter:SOCD) and soil in-organic carbon density(hereafter:SIOCD) at different soil depths were computed using the following equations:

$$
\begin{aligned}
& \operatorname{SOCD}(i)=\frac{\operatorname{SOC}(i) \times B D(i) \times H(i)}{10} \\
& \operatorname{SIOCD}(i)=\frac{\operatorname{SIOC}(i) \times B D(i) \times H(i)}{10}(2)
\end{aligned}
$$

Where SOC(i) and SIOC(i) is the content of $\mathrm{SOC}(\%)$ and $\mathrm{CaCO}_{3}(\%)$ in the depth i respectively, $\mathrm{BD}(\mathrm{i})$ is the soil bulk density $\left(\mathrm{g} / \mathrm{cm}^{3}\right)$ in the depth $\mathrm{i}, \mathrm{H}(\mathrm{i})$ is the soil layer's thickness $(10 \mathrm{~cm})$. the diagrams in the paper were drawn with ggplot2 packages of R (R Core Team ,2019) and Excel 2013.

\section{Results}

\section{1 aggregates stability characteristics}

\subsubsection{Mean weight diameter $(\mathrm{mm})$ under dry-sieving condition}

Mean weight diameter of aggregation distribution under the condition of dry sieving (noted as MWD_dry) was calculated using the formula (1) and the results were shown on the top (corresponding 0) in Fig. 1. Dry aggregate distribution was significantly affected by plantation types and soil layers. Compared to M.pumila, the MWD_dry in P.tabuliformis and R. Pseudoacaciaplantations significantly decreased, especially at the deep soils. MWD_dry was $3.25-7.17 \mathrm{~mm}, 2.69-5.58 \mathrm{~mm}$ and $6.64-8.64 \mathrm{~mm}$ in P.tabuliformis , R. Pseudoacacia and M.pumilaplantations respectively, which tended to decrease inP.tabuliformis but fluctuated in R. Pseudoacacia and M.pumila plantations with soil layer's deepening.

\subsubsection{Mean weight diameter $(\mathrm{mm})$ under the wet sieving condition}

Soil aggregates with different initial diameter such as $<1.2 \mathrm{~mm}, 1.2-2.0 \mathrm{~mm}, 2.0-5.0 \mathrm{~mm}$ and $5.0-7.0 \mathrm{~mm}$ were fast wetted, and then water stability of them was measured by $\mathrm{MWD}$, denoted by $\mathrm{MWD}_{<1.2 \mathrm{~mm}}$, $\mathrm{MWD}_{1.2-2.0 \mathrm{~mm}}, \mathrm{MWD}_{2-5 \mathrm{~mm}}, \mathrm{MWD}_{5-7 \mathrm{~mm}}$, corresponding the number $1,2,3,4$ on the right side of Fig.1 respectively. The average of $\mathrm{MWD}_{<1.2 \mathrm{~mm}}, \mathrm{MWD}_{1.2-2.0 \mathrm{~mm}}, \mathrm{MWD}_{2-5 \mathrm{~mm}}, \mathrm{MWD}_{5-7 \mathrm{~mm}}$ was $0.19 \mathrm{~mm}, 0.19 \mathrm{~mm}, 0.24$ $\mathrm{mm}, 0.36 \mathrm{~mm}$ at $R$. pseudoacacia $, 0.32 \mathrm{~mm}, 0.40 \mathrm{~mm}, 0.50 \mathrm{~mm}, 0.66 \mathrm{~mm}$ at P.tabuliformis and $0.12 \mathrm{~mm}$, $0.15 \mathrm{~mm}, 0.14 \mathrm{~mm}, 0.26 \mathrm{~mm}$ at M.pumila respectively. MWD increased proportionally with the increase of initial diameter. MWDs were significant higher inP.tabuliformis compared to R. pseudoacacia andM.pumila , especially in the subsurface layers (Fig.1). MWDs were in the order of P.tabuliformis $>R$. pseudoacacia $>$ M.pumila. In the M.pumilaplantation, maximal MWD dry and minimal MWD with different initial diamters showed more dry macro-aggregates were easily disrupted by water into smaller ones compared to P.tabuliformisand R. pseudoacacia .

\subsection{The content of soil organic matter and in-organic carbon}

Our findings showed that average $26.35 \%, 30.65 \%$ and $30.91 \%$ of SOM were distributed in the top soil $(0-10 \mathrm{~cm})$ in P. tabuliformis , R. pseudoacacia and M.pumila plantations respectively. Meaning while, the differences of SOM content were smaller in the subsurface layers $(10-60 \mathrm{~cm})$ than the surface layer $(0-10$ $\mathrm{cm}$ ) between plantations of $R$.pseudoacacia and M.pumila. However, in all soil layers, the SOM content was significantly higher in $P$. tabuliformis forest than in $R$. pseudoacacia and M.pumila forests (Fig.2A). The content of soil in-organic carbon was expressed by the percentage of calcium carbonate $\left(\mathrm{CaCO}_{3}\right)(\mathrm{Fig} .2 \mathrm{~B})$. The content of $\mathrm{CaCO}_{3}$ varied from 19.41 to $22.72 \%$ in R. pseudoacacia plantation, from 12.34 to $14.10 \%$ in M.pumila plantation, and from 3.42 to $9.90 \%$ in $P$. tabuliformis plantation, showing the order of $R$. pseudoacacia $>$ M.pumila $>P$. tabuliformis . The content of $\mathrm{CaCO}_{3}$ in $R$. pseudoacacia plantation was 2.225.67 times that of $P$. tabuliformis plantation in different soil layers. Carbonate content varied among the 
three forest types - despite all soils being developed over loess parent material rich in carbonate materialsmainly due to tree types.

\subsection{The relationships among the MWDs and SOM}

The relationships were examined by a matrix of scatterplots (Fig.3). Four kinds of MWD with different initial diameter were positively correlated with each other. The significant correlation coefficients were observed between $\mathrm{MWD}_{<1.2 \mathrm{~mm}}$ and $\mathrm{MWD}_{1.2-2 \mathrm{~mm}}(\mathrm{r}=0.95), \mathrm{MWD}_{<1.2 \mathrm{~mm}}$ and $\mathrm{MWD}_{2-5 \mathrm{~mm}}(\mathrm{r}=0.95), \mathrm{MWD}_{<1.2 \mathrm{~mm}}$ and $\mathrm{MWD}_{5-7 \mathrm{~mm}}(\mathrm{r}=0.92), \mathrm{MWD}_{1.2-2 \mathrm{~mm}}$ and $\mathrm{MWD}_{<2-5 \mathrm{~mm}}(0.96), \mathrm{MWD}_{1.2-2 \mathrm{~mm}}$ and $\mathrm{MWD}_{5-7 \mathrm{~mm}}(0.95), \mathrm{MWD}_{2-5 \mathrm{~mm}}$ and $\mathrm{MWD}_{5-7 \mathrm{~mm}}(0.95) . \mathrm{MWD}_{<1.2 \mathrm{~mm}}, \mathrm{MWD}_{1.2-2 \mathrm{~mm}}, \mathrm{MWD}_{2-5 \mathrm{~mm}}$ and $\mathrm{MWD}_{5-7 \mathrm{~mm}}$ were positively correlated with the SOM, but the correlation coefficient successively decreased with the increase of initial diameter.

\subsection{Bulk density characteristics}

In M.pumila plantation, the bulk density varied between 1.41 and $1.56 \mathrm{~g} / \mathrm{cm}^{3}$, which ranged between 0.91 and $1.31 \mathrm{~g} / \mathrm{cm}^{3}$ in P. tabuliformis forest, and from 1.16 to $1.48 \mathrm{~g} / \mathrm{cm}^{3}$ in $R$. pseudoacacia forest (Fig.4). Bulk density was always higher in M.pumila forest than in the two others in the whole soil layers. The bulk density in $0-10,10-20,20-30,30-40,40-50,50-60$ and $60-70 \mathrm{~cm}$ of $P$. tabuliformisforest declined by 21.43, $0.55,18.15,13.52,11.44,12.64$ and $28.23 \%$ relative to that of $R$. pseudoacacia forest, and decreased by 35.41 , $20.79,23.18,19.50,12.17$ and $17.53 \%$ in the first five soil layers compared with M.pumila forest respectively.

\section{5 soil organic carbon density and soil in-organic carbon density}

At the soil profiles, soil in-organic carbon density (SIOCD) increased gradually to a maximum value and then declined step by step. However, the peak was attained at different soil layer depending on the three forest types (Fig.5). Soil organic carbon density (SOCD) was highest at the surface soil and the distribution pattern was similar to SOM. The average SOCD and SIOCD were $0.97(\mathrm{SD}=0.46)$ and $29.76(\mathrm{SD}=3.61)$, $1.58(\mathrm{SD}=0.49)$ and $8.85(\mathrm{SD}=2.87), 1.06(\mathrm{SD}=0.43)$ and $19.97(\mathrm{SD}=1.67) \mathrm{kg} / \mathrm{m}^{2}$ at soil profiles of $R$. pseudoacacia , P. tabuliformis , M.pumila plantation respectively. SOCD was negatively correlated with SIOCD. Soil total carbon density (STCD) were calculated by SOCD plus SIOCD (Fig.6). The ratios of SOCD to STCD were 2.03-8.49\%, 8.90-45.89\%, 3.59-9.59\% in R. pseudoacacia ,P. tabuliformis , M.pumila plantations respectively. However, SIOCD to STCD ratios were 91.51-97.97\%, 54.11-91.10\%, 90.41-96.41\% successively. STCD were the highest at the $R$. pseudoacacia forest, intermediate at M.pumila forest, and the lowest at $P$. tabuliformisforest (Fig.6).

The STCD fluctuated with deepening soil layers, which in the 0-10,10-20, 20-30, 30-40, 40-50, 50-60, 6070 and $70-80 \mathrm{~cm}$ of $R$. pseudoacaciaforest were $326.89 \%, 215.37 \%, 213.50 \%, 187.81 \%, 135.97 \%, 188.22 \%$, $187.13 \%, 189.79 \%$ higher than that of $P$. tabuliformis forest. The STCD in 0-10,10-20, 20-30, 30-40, 40-50, 50-60 of M.pumilaforest were $234.23 \%, 143.68 \%, 122.65 \%, 104.15 \%, 37.55 \%, 70.85 \%$ higher than that of $P$. tabuliformis forest.

\subsection{The content of soil organic matter and in-organic carbon in water stable aggregate with} different size

The $\mathrm{CaCO}_{3}$ content declined successively with increasing aggregate size and was the lowest in $>2 \mathrm{~mm}$ fraction (Fig.6). Inversely, the SOM content increased linearly with the increase in aggregate size, and the highest was in $>2 \mathrm{~mm}$ fraction $(3.93 \%)$ (Fig. 7 ). It was obvious that there was a trade off between SOM and $\mathrm{CaCO}_{3}$ content.

\section{Discussion}

An evaluation of the changes in soil properties as a consequence of forest planting is important, especially for fragile ecological areas (Gu et al.,2019). Our results supported the hypothesis that bulk density, aggregates stability and the content of carbon were affected by tree species, and they also changed obviously at soil layers. Additionally, water stable aggregates with bigger sizes had more soil organic matter con-

tent, but less calcium carbonate content. The total carbon density was in the order of $R$. pseudoacacia $>$ M.pumila $>$ P. tabuliformis in all soil layers. On the one hand, R. pseudoacacia plantation contributed 
more carbon sequestration relative to $M$. pumila and $P$. tabuliformis plantations, but on the other hand, P.tabuliformisplantation was more conducive to accumulation of soil organic carbon, reduction of soil inorganic carbon and bulk density. It also could improve the water stability of soil aggregates, which will facilitate the improvement of soil quality and protection of soil and water from loss.

\subsection{Changes in soil properties among three tree species}

Soil aggregate stability is considered to be a property that provides information on soil quality(Chrenkova et al., 2014). In addition, many studied soil parameters aligned with SOM (Zethof et al.,2019), especially such as aggregate stability. It was observed that water stability of soil aggregates and SOM content both were in the order of $P$. tabuliformis $>R$. pseudoacacia $>$ M.pumila, indicating that soil quality and related soil functions varied greatly among three species. Similarly, Chen et al. (2016) found that soil organic carbon was higher in 10-year-old $P$. tabulaeformis than in 10-year-old R.pseudoacaciastands. In our study, it was demonstrated that $P$. tabuliformiswould be more conducive to increase of SOM and improvement of aggregate stability compared with $R$. pseudoacacia and M.pumila. This is in agreement with results found by previous studies, which observedPinus plant could supply soil with considerably more organic material and improve water repellency of soil (Doerr et al. 2000; Mataix-Solera et al. 2007; Lozano et al. 2013; Chrenkova et al. 2014). Increase in SOM was mostly associated with an increase in soil hydrophobicity, especially under the wax/aromatic oil rich litter of thePinus halepensis trees (Mataix-Solera et al., 2007). Moreover, the presence of water repellency can play an important role in the formation and stabilization of aggregates and can avoid high levels of soil degradation (Chrenkova et al., 2014). From this, it seemed logical that soil quality indicators including SOM and aggregate stability have been improved by P. tabuliformis plantation in the present study. Additionally, the average fine root biomass (FRB) and fine root production (FRP) of P.tabulaeformis were greater than those of $R$. pseudoacacia (Chen et al.,2016). Small and fine roots produced optimal conditions to form and stabilize aggregates due to the polysaccharides being produced by the microorganisms (Boix-Fayos et al.,2001). Meanwhile, BD was significantly related to most other soil parameters and it could be used as an indicator of soil structure (Gu et al.,2019). The soil BD was in the order of $P$. tabuliformis $<R$. pseudoacacia $<$ M.pumila, which indicated there were negative correlation between BD and MWD, SOM. Our study demonstrated that the increase of SOM corresponds to the improvement of aggregate stability and decrease of $\mathrm{BD}$, which was particularly significant in $P$. tabulaeformis plantation, and R. pseudoacacia plantation followed. At M. pumila plantation, MWD of dry-sieving aggregates was the largest, however, MWD of water stable aggregates was the smallest (Fig.1), which was similar with the lowest SOM (Fig.2). It was visible that lowest values of SOM and MWD under the condition of wet sieving, and highest bulk density were present in M.pumila plantation. This could be explained by long term cultivation management such as pruning and weed control resulting in the lower input and higher decomposition of organic substances. Lal (2008) also believed that most soil under the managed ecosystems contained a lower SOC pool than their counterparts under natural ecosystems due to the depletion of the SOC pool in cultivated soil. Our findings also showed that soil organic matter was largest significantly in the top 0-10 cm compared to the other soil layers. This was in agreement with previous studies conducted in other forest ecosystems (Huntington, 1995; Han et al., 2018), and was a logical result as the surface layer is the main place of soil organic matter sources such as dry branches and fallen leaves.

\section{2 effect of tree species on soil carbon sequestration}

It is also becoming increasingly clear that carbon accumulation in soil represents an important carbon stocks (Huntington, 1995). The quantitative relationship between the changes of SOC and SIC stocks in deep profiles following vegetation restoration should be further determined (Han et al.,2018). Our results showed large ranges in both SOCD $\left(0.64-2.63 \mathrm{~kg} / \mathrm{m}^{2}\right)$ and SIOCD $\left(3.11-33.96 \mathrm{~kg} / \mathrm{m}^{2}\right)$ over the $0-80 \mathrm{~cm}$ soil profiles. Wang et al.(2015) also found large ranges in both SOC $\left(1-12 \mathrm{~kg} / \mathrm{m}^{2}\right)$ and SIC stocks $\left(6-45 \mathrm{~kg} / \mathrm{m}^{2}\right)$ over the 0-100 cm in northwest of China. Compared with P. tabulaeformis , The STCD increased by 135.97\%$326.89 \%$ and $37.55 \%-234.23 \%$ in $R$. pseudoacacia and M. pumila plantations respectively. The result was in agreement with that, found by Hyun-Kil et al.(2013), mean $\mathrm{CO}_{2}$ storage per unit area was higher in broadleaved than coniferous forests for the same age classes. The result of SIOCD to STCD ratios indicated 
that inorganic carbon stocks was much larger than that of organic carbon, especially in $R$. pseudoacacia and M. pumila plantations. Zethof et al. (2019) and Wang et al. (2015) also found inorganic carbon stocks were often much larger than organic carbon stocks in semi-arid regions. Our results also revealed a negative correlation between SOCD with SIOCD (Fig.5), and between SOM with $\mathrm{CaCO}_{3}$ (Fig.7). This was because (1) decomposition of higher SOM under P. tabulaeformis plantation produced higher $\mathrm{CO}_{2}$ concentration in soil, which would produce both $\mathrm{HCO}_{3}{ }^{-}$and $\mathrm{H}{ }^{+}$, and then more carbonate would be dissolved (Wang et al.,2015); (2) higher organic matter accumulation increased saturated hydraulic conductivity(Gu et al.,2019), which also increased carbonates leaching. In general, there was a trade-off between $\mathrm{SOM}$ and $\mathrm{CaCO}_{3}$, which was similar to the conclusions of Yang et al.(2018) and Han et al.(2018). The SIOCD fluctuated with deepening soil layers, showing subsoil was an important sink for carbon (Bhattacharya et al.,2016). Han et al.(2018) also confirmed that the maximum soil in-organic carbon(SIC) values was at $60-100 \mathrm{~cm}$ soil layer. SIC content at subsoil increased significantly due to more pedogenic carbonate formed by $\mathrm{Ca}^{2+}$ derived from the decomposed litter and biogenic $\mathrm{CO}_{2}$ (Zhang et al.,2018b) or the dissolution and leaching of carbonates from topsoil and the subsequent precipitation in the subsoil (Yang et al.,2018). There was a lot more carbon in deep soil than we once thought, and the underlying processes inhibiting its turnover are still largely unknown (Schmidt et al.,2011).

\subsection{Aggregate- $\mathrm{CaCO}_{3}$ content decreased with increasing aggregate size}

In many semi-arid regions, where the presence of carbonates in soil is frequent, it is necessary to study the correlation between carbonates and aggregate stability. For example, Fernandez-Ugalde et al. (2011) thought carbonates must be considered when modelling soil structure formation. Calcium bridging is the dominant factor for the long-term positive effect of calcium addition on the structural stability of soil (six et al., 2004). Chrenkova et al.(2014) found carbonate content had a positive influence in MWD for sandy soils. In semi-arid calcareous soils, Fernandez-Ugalde et al. (2011) found that the interaction of maize straw and carbonates resulted in a higher stability of macro-aggregates $(>250 \mathrm{um})$ in carbonated soil than non-carbonated soil, then concluded the formation of secondary carbonates within and/or around macro-aggregate could explain this stability. However, in our case, the effect of carbonates in stabilization of aggregates was not found. On the contrary, aggregate-inorganic carbon decreased with increasing aggregate size, except for the smallest size which had lower concentration than the next-bigger size. This occurred because the $\mathrm{CaCO}_{3}$ could make the soil particles consolidated in the dry state. But when soil was wetted by water, the $\mathrm{CaCO}_{3}$ could dissolve in water and make the soil particles separated and become dispersed. Therefore, the calcareous soil was vulnerable to erosion in our study. Our study also found that planting P. tabulaeformis could effectively decrease the content of soil $\mathrm{CaCO}_{3}$, which lead to the improvement of soil stability and reducing of soil erosion.

\subsection{Aggregate-SOM content increased with increasing aggregate size}

Qiao et al.(2016) suggested that micro-aggregates played key roles in protecting SOC based on more recalcitrant SOC stored in micro-aggregates. However, higher organic carbon content in the macro-aggregates ( $>2 \mathrm{~mm}$ fraction) compared to the micro-aggregates $(<0.2 \mathrm{~mm}$ fraction) in our results, that was similar to previous studies (Fernandez-Ugalde et al.,2011), which observed that when organic inputs were increased in a calcareous soil, a greater proportion of stable macro-aggregate $(>250 \mathrm{um})$ would be formed in comparison to a non-calcareous soil of similar characteristics. Ellitt (1986) observed more organic matter associated with macro-aggregates than with micro-aggregates in a temperature grassland soil. The conclusion also was line with the theory of aggregate hierarchy, which believes an increase in carbon concentration with increasing aggregates size class because that large aggregate-size classes are composed of small aggregate-size classes plus organic binging agents (Elliott, 1986).

\section{Conclusion}

Organic materials are the major cementing agents while inorganic carbon (e.g. Calcium carbonate) may be a dispersing agent influencing aggregation formation and stabilization. MWDs with different initial diameter significantly positive correlated and increased with the increase of initial diameter. Soil organic carbon and 
inorganic carbon were affected by tree species. The economic forest $M$. pumiladecreased the content of SOM and MWD of water stable aggregates due to effect of management. M. pumila and $R$. pseudoacacia were not as beneficial as $P$. tabulaeformis for the accumulation of SOM and improving water stable aggregates. However, R. pseudoacaciacan sequestrate more carbon than P. tabulaeformis and M. pumila.

\section{Acknowledgements}

This study was supported by the project of National Natural Science Foundation of China (41907053);Special Research Foundation Project of Xianyang Normal University (XSYK19027).We acknowledged the assistance of Environmental analysis laboratory of Xianyang Normal University. We would like to thank our students Lei Ning, Feng Yuqin Liu luonan, Sun Mengyao and Zhang Yuning for their help of field sampling and laboratory experiments. We also wish to thank for anonymous referees for their constructive suggestions and improvements.

\section{References}

Ahmadi, A., Neyshabouri, M. R., Rouhipour, H., \& Asadi, H. (2011). Fractal dimension of soil aggregates as an index of soil erodibility. Journal of Hydrology, 400: 305-311. https://doi.org/10.1016/j.jhydrol.2011.01.045

Bhattacharya, S. S., Kim, K. H., Das, S., Uchimiya, M., Jeon, B. H., Kwon, E.,\& Szulejko, J. E. (2016). A review on the role of organic inputs in maintaining the soil carbon pool of the terrestrial ecosystem. Journal of Environmental Management, 167: 214-227. http://dx.doi.org/10.1016/j.jenvman.2015.09.042

Boix-Fayos, C., Calvo-Cases, A., Imeson, A. C., \& Soriano-Soto, M. D. (2001). Influence of soil properties on the aggregation of some Mediterranean soils and the use of aggregate size and stability as land degradation indicators. Catena, $44: 47-67$.

Briedis, C., Sa, M. J. C., Caires, E. F., Navarro, J. F., Inagaki, T.M., Boer, A., Neto, C.Q., Ferreira, A.O., Canalli, L.B., \&Santos, J.B. (2012). Soil organic matter pools and carbon-protection mechanisms in aggregate classes influenced by surface liming in a no-till system. Geoderma, 170: 80-88. https://doi.org/10.1016/j.geoderma.2011.

Cao, Y., Li, Y. N., \& Chen, Y. M.(2018a). Non-structural carbon, nitrogen, and phosphorus between black locust and chinese pine plantations along a precipitation gradient on the Loess Plateau, China. Trees, 32: 835-846. https://doi.org/10.1007/s00468-018-1676-1

Cao, Y., Zhang, P., \& Chen, Y. M. (2018b). Soil C:N:P stoichiometry in plantations of N-fixing black locust and indigenous pine, and secondary oak forests in Northwest China. Journal of Soils and Sediments, 18(2): 1478-1489. https://doi.org/10.1007/s11368-017-1884-0

Chai, Y. J., Zeng, X. B., E, S.Z., Che, Z. X., Bai, L.Y., Su, S. M., \& Wang, Y. N. (2019). The stability mechanism for organic carbon of aggregate fractions in the irrigated desert soil based on the long-term fertilizer experiment of China. Catena, 173: 312-320. https://doi.org/10.1016/j.catena.2018.10.026

Chen, L. L., Deng, Q., Yuan, Z. Y., Mu, X. M.,\& Kallenbach, R. L. (2018). Age-related C:N:P stoichiometry in two plantation forests in the Loess Plateau of China. Ecological Engineering, 120: 14-22. https://doi.org/10.1016/j.ecoleng.2018.05.021

Chen, L. L., Mu, X. M., Yuan, Z. Y., Deng, Q., Chen, Y.L., Yuan, L.Y., Ryan, L.T., \& Kallenbach, R.L. (2016). Soil nutrients and water affect the age-related fine root biomass but not production in two plantation forests on the Loess Plateau, China. Journal of Arid Environments, 135:173-180. http://dx.doi.org/10.1016/j.jaridenv.2016.09

Chrenkova, K., Mataix-Solera, J., Dlapa, P., \& Arcenegui, V. (2014). Long-term changes in soil aggregation comparing forest and agricultural land use in different Mediterranean soil types. Geoderma, 235: 290-299. http://dx.doi.org/10.1016/j.geoderma.2014.

07.025

Doerr, S. H., Shakesby, R. A., \&Walsh, R. P. D. (2000). Soil water repellency: its causes, characteristics and hydro-geomorphological significance. Earth Science Reviews, 51: 33-65. 
Du, Z. L., Ren, T. S., Hu, C. S., Zhang, Q.Z., \& Humberto, B.C. (2013). Soil aggregate stability and aggregate-associated carbon under different tillage systems in the north China plain. Journal of Integrative Agriculture, 12(11): 2114-2123. https://doi.org/ 10.1016/j.geoderma.2011.06.008

Elliott, E. T. (1986). Aggregate structure and carbon, nitrogen, and phosphorus in native and cultivated soils. Soil Science Society of America Journa, 50(3): 627-633.

Fernandez-Ugalde, O., Virto, I., Barre, P., Gartzia-Bengoetxea, N., Enrique, A., Imaz, M. J., \& Bescansa, P.(2011). Effect of carbonates on the hierarchical model of aggregation in calcareous semi-arid Mediterranean soils. Geoderma, 164(3-4): 203-214. https://doi.org/10.1016/j.geoderma.2011.06.008

Gu, C. J., Mu, X. M., Gao, P., Zhao, G. J., Sun, W.Y., Tatarko, J., \& Tan, X. J. (2019). Influence of vegetation restoration on soil physical properties in the Loess Plateau, China. Journal of Soils and Sediments,19: 716-728. https://doi.org/10.1007/s11368-018-2083-3

Han, X. Y., Gao, G. Y., Chang, R. Y., Li, Z.S., Ma, Y., Wang, S., Wang, C., Lu, Y.H., \& Fu, B.J. (2018). Changes in soil organic and inorganic carbon stocks in deep profiles following cropland abandonment along a precipitation gradient across the Loess Plateau of China. Agriculture, Ecosystems and Environment, 258: 1-13. https://doi.org/10.1016/j.agee.2018.02.006

Huntington, T. G. (1995). Carbon sequestration in an aggrading forest ecosystem in the southeastern USA. Soil Science Society of America Journal, 59(5): 1459-1467.

Hyun-Kil, J., \& Tae-Won, A. (2013). Evaluation of $\mathrm{CO}_{2}$ storage and uptake by forest landscapes in the middle region of Korea. Journal of Environmental Science International, 22(2): 139-149. http://dx.doi.org/10.5322/JESI.2013.22.2.1?

Lal, R. (2008). Carbon sequestration. Philosophical Transactions of the Royal Society Biological Sciences, 363: 815-830. https://doi.org/10.1098/rstb.2007.2185

Li, T. J., \& Liu, G. B. (2014). Age-related changes of carbon accumulation and allocation in plants and soil of black locust forest on Loess Plateau in Ansai County, Shaanxi Province of China. Chinese Geographical Science, 24(4): 414-422. https://doi.org/10.1007/s11769-014-0704-3

Liu, M. Y., Chang, Q. R., Qi, Y. B., Liu, J. \& Chen, T. (2014). Aggregation and soil organic carbon fractions under different land uses on the tableland of the Loess Plateau of China. Catena, 115: 19-28. http://dx.doi.org/10.1016/j.catena.2013.11.002

Liu, Y. Q., Wei, X. H., Guo, X. M., Niu, D.K., Zhang, J.X., Gong, X., \& Jiang, Y.M. (2012). The long-term effects of reforestation on soil microbial biomass carbon in sub-tropic severe red soil degradation areas. Forest Ecology and Management, 285: 77-84. http://dx.doi.org/10.1016/j.foreco.2012.08.019

Lozano, E., Jimenez-Pinilla, P., Mataix-Solera, J., Arcenegui, V., Barcenas, G. M., Gonzalez-Perez, J.A., Garcia-Orenes, F., Torres, M. P., \& Mataix-Beneyto, J. (2013). Biological and chemical factors controlling the patchy distribution of soil water repellency among plant species in a Mediterranean semiarid forest. Geoderma, 207-208: 212-220. http://dx.doi.org/10.1016/j.geoderma.2013.

05.021

Mataix-Solera, J., Arcenegui, V., Guerrero, C., Mayoral, A. M., Morales, J., Gonzalez, J., Garcia-Orenes, F., \& Gomez, I. (2007). Water repellency under different plant species in a calcareous forest soil in a semiarid Mediterranean environment. Hydrological. Process, 21: 2300-2309. https://doi.org/10.1002/hyp.6750

Nie, X. D., Li, Z. W., Huang, J. Q., Huang, B., Xiao, H.B., \&Zeng, G.M. (2017). Soil organic carbon fractions and stocks respond to restoration measures in degraded lands by water erosion. Environmental Management, 59: 816-825. https://doi.org/ 10.1007/s00267-016-0817-9

Qiao, Y. F., Miao, S. J., Yue, S. P., Wu, H.Y., \& Han, X. Z. (2016). How 23-year continuous soybean cultivation led to more SOC and thermal energy atored in Mollisol micro-aggregates. Polish Journal of Environmental Studies,25(3):1215-1221. https://doi.org/10.15244/pjoes/61628 
R Core Team. (2019). R: A language and environment for statistical computing. R Foundation for Statistical Computing, Vienna, Austria. URL https://www.R-project.org/.

Schmidt, M. W. I., Torn, M. S., Abiven, S., Dittmar, T., Guggenberger, G., Janssens, I. A., Kleber, M., Kögel-Knabner, I., Lehmann J., Manning, D. A. C., Nannipieri, P., Rasse, D. P., Weiner, S., \& Trumbore, S. E.. (2011). Persistence of soil organic matter as an ecosystem property. Nature, 478(7367): 49-56. https://doi.org/10.1038/natu

Shu, X., Zhu, A. N., Zhang, J. B., Yang, W.L., Xin, X.L., \& Zhang, X.F. (2015). Changes in soil organic carbon and aggregate stability after conversion to conservation tillage for seven years in the Huang-Huai-Hai plain of China. Journal of Integrative Agriculture,14(6): 1202-1211. https://doi.org/10.1016/S2095-3119(14)60862-5

Six, J., Bossuyt, H., Degryze, S., \& Denef, K. (2004). A history of research on the link between (micro) aggregates, soil biota, and soil organic matter dynamics. Soil \&Tillage Research, 79(1): 7-31. https://doi.org/10.1016/j.still.200

Tong, X. G., Han, X. H., Wu, F. Q., Zhao, F. Z., Ren, C.J., \& Li, J.et al. (2016). Change in carbon storage in soil physical fractions after afforestation of former arable land. Soil Science Society of American Journal. 80(4): 1098-1106. https://doi.org/ 10.2136/sssaj2015.12.0433

Thomaz, E. L. (2017). Fire changes the larger aggregate size classes in slash-and-burn agricultural systems. Soil \& Tillage Research, 165: 210-217. http://dx.doi.org/10.1016/j.still.2016.08.018

Wang, F. M., Li, Z. A., Xia, H. P., Zou, B., Li, N.Y., Liu, J., \& Zhu, W. X. (2010). Effects of nitrogenfixing and non-nitrogen-fixing tree species on soil properties and nitrogen transformation during forest restoration in southern China, Soil Science \& Plant Nutrition, 56(2): 297-306. https://doi.org/10.1111/j.17470765.2010.00454.x

Wang, X. J., Wang, J. P., Xu, M. G., Zhang, W.J., Fan, T.L., \& Zhang, J. (2015). Carbon accumulation in arid croplands of northwest China: pedogenic carbonate exceeding organic carbon. Scientific Reports, 5 : 11439. https://doi.org/ 10.1038/srep11439

Xiao, Y., An, K., Xie, G. D., Lu, C.X., \& Zhang, B. (2011). Carbon sequestration in forest vegetation of Beijing at sublot level. Chinese Geographical Science, 21(3) : 279-289.https://doi.org/ 10.1007/s11769-0110469-x

Xie, J. Y., Xu, M. G., Ciren, Q., Yang, Y., Zhang, S.L., Sun, B.H., \& Yang, X.Y. (2015). Soil aggregation and aggregate associated organic carbon and total nitrogen under long-term contrasting soil management regimes in loess soil. Journal of Integrative Agriculture, 14(12): 2405-2416. https://doi.org/ 10.1016/S2095$3119(15) 61205-9$

Yang, F., Huang, L. M., Yang, R. M., Yang, F., Li, D.C., Zhao, Y.G., Yang, J.L., Liu, F., \& Zhang, G.L. (2018). Vertical distribution and storage of soil organic and inorganic carbon in a typical inland river basin, Northwest China. Journal of Arid Land, 10(2): 183-201. https://doi.org/10.1007/s40333-018-0051-9

Zhang, W., Qiao, W. J., Gao, D. X., Dai, Y.Y., Deng, J., Yang, G.H., Han, X.H., \& Ren, G.X.(2018a). Relationship between soil nutrient properties and biological activities along a restoration chronosequence of Pinus tabulaeformis plantation forests in the Ziwuling Mountains, China. Catena, 161: 85-95. http://dx.doi.org/10.1016/j.cater

Zhang, L., Zhao, W., Zhang, R., Cao, H., \& Tan, W.F. (2018b). Profile distribution of soil organic and inorganic carbon following revegetation on the Loess Plateau, China. Environmental Science and Pollution Research, 25(30):30301-30314. https://doi.org/10.1007/s11356-018-3020-0

Zethof, J. H. T., Cammeraat, E. L. H., \& Nadal-Romero, E. (2019). The enhancing effect of afforestation over secondary succession on soil quality under semiarid climate conditions. Science of the Total Environment, 652:1090-1101. https://doi.org/10.1016/j.scitotenv.2018.10.235 


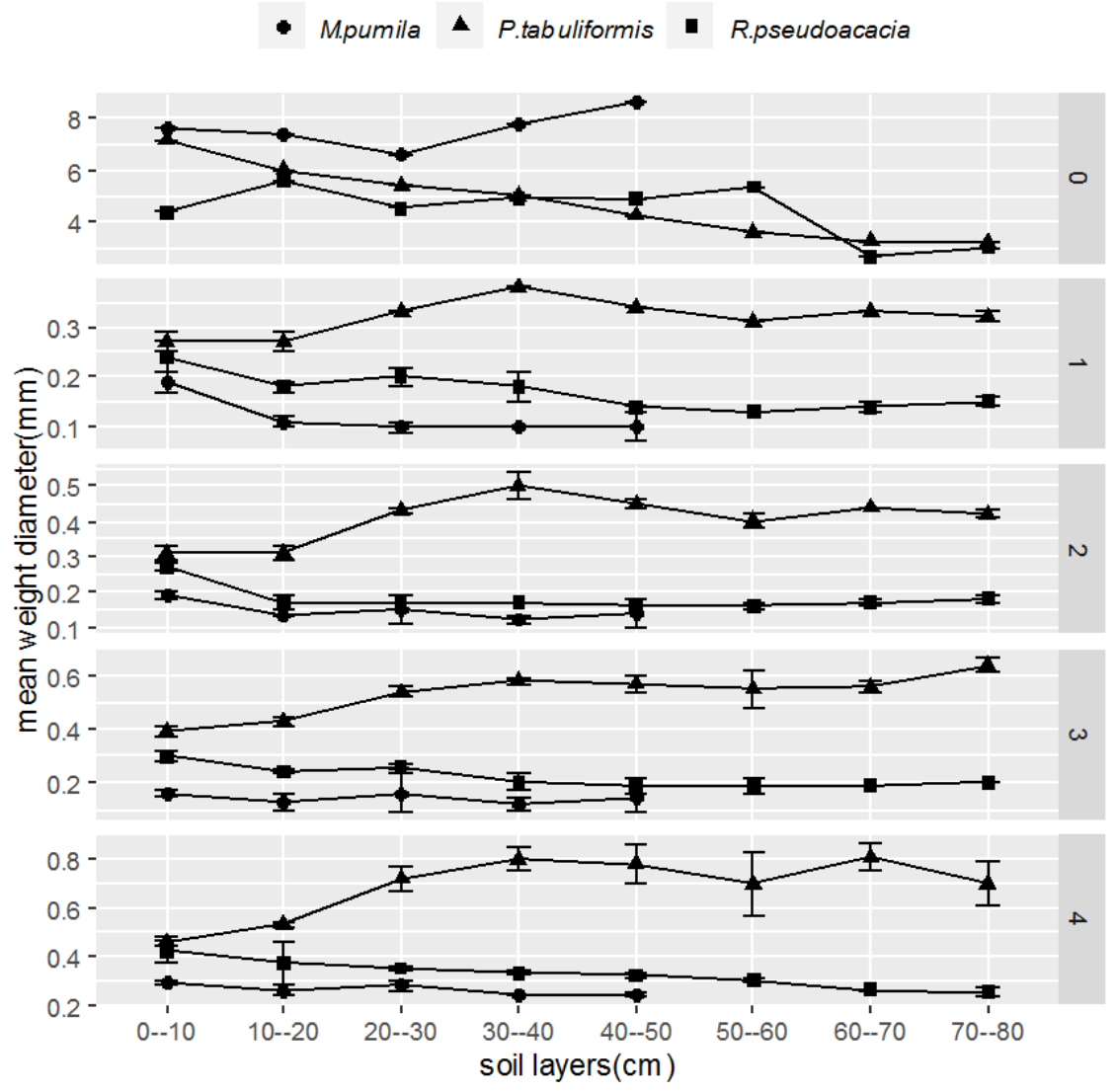




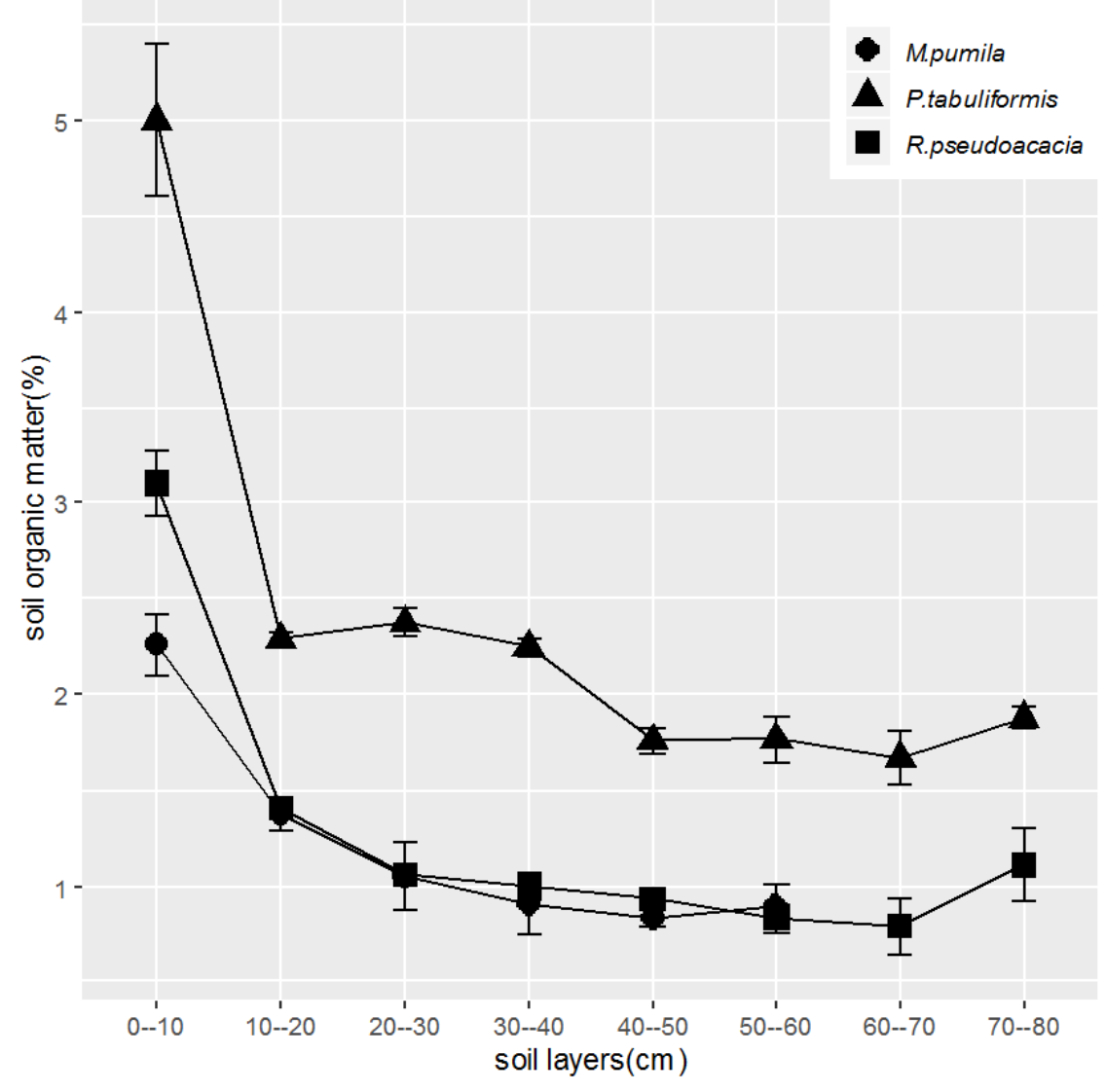




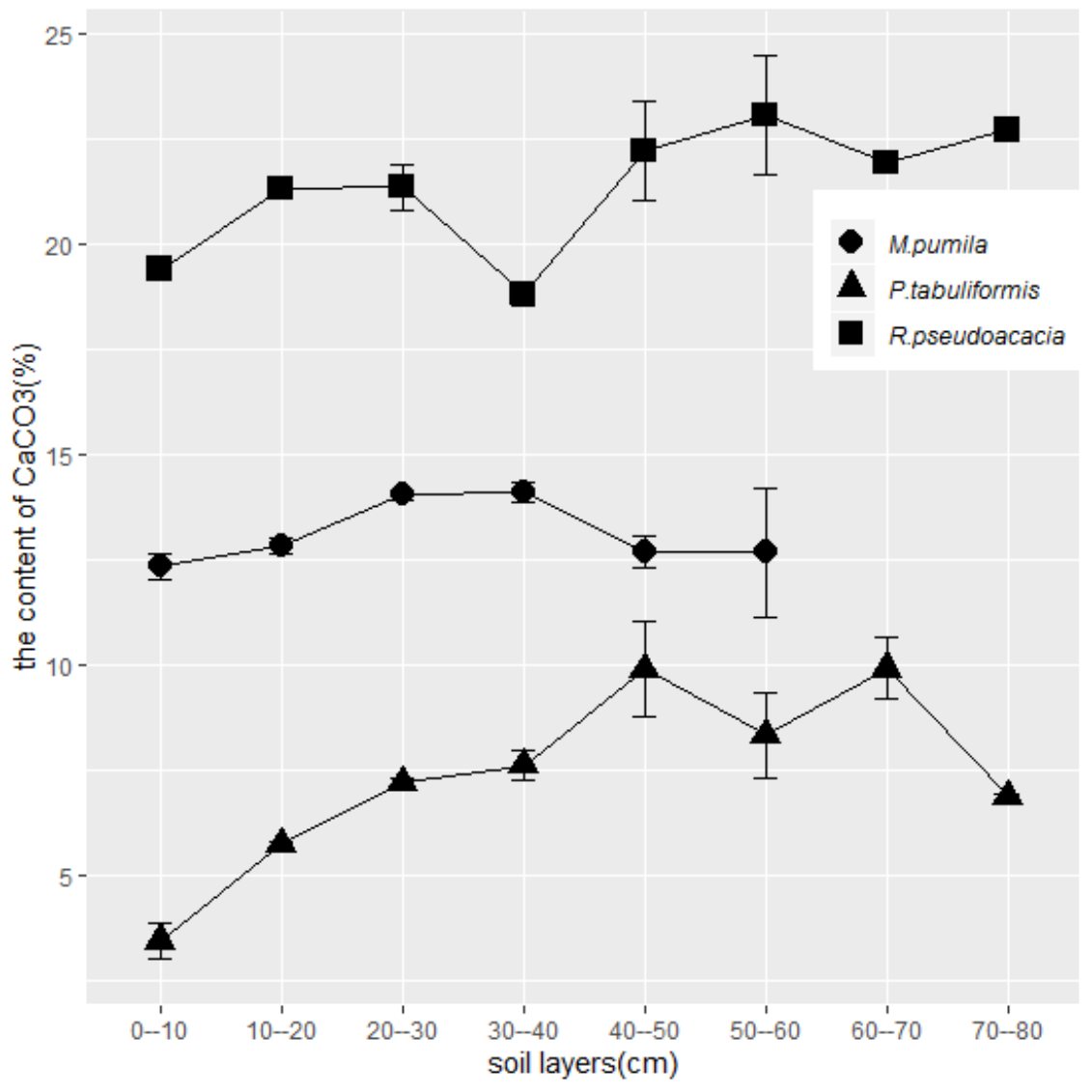




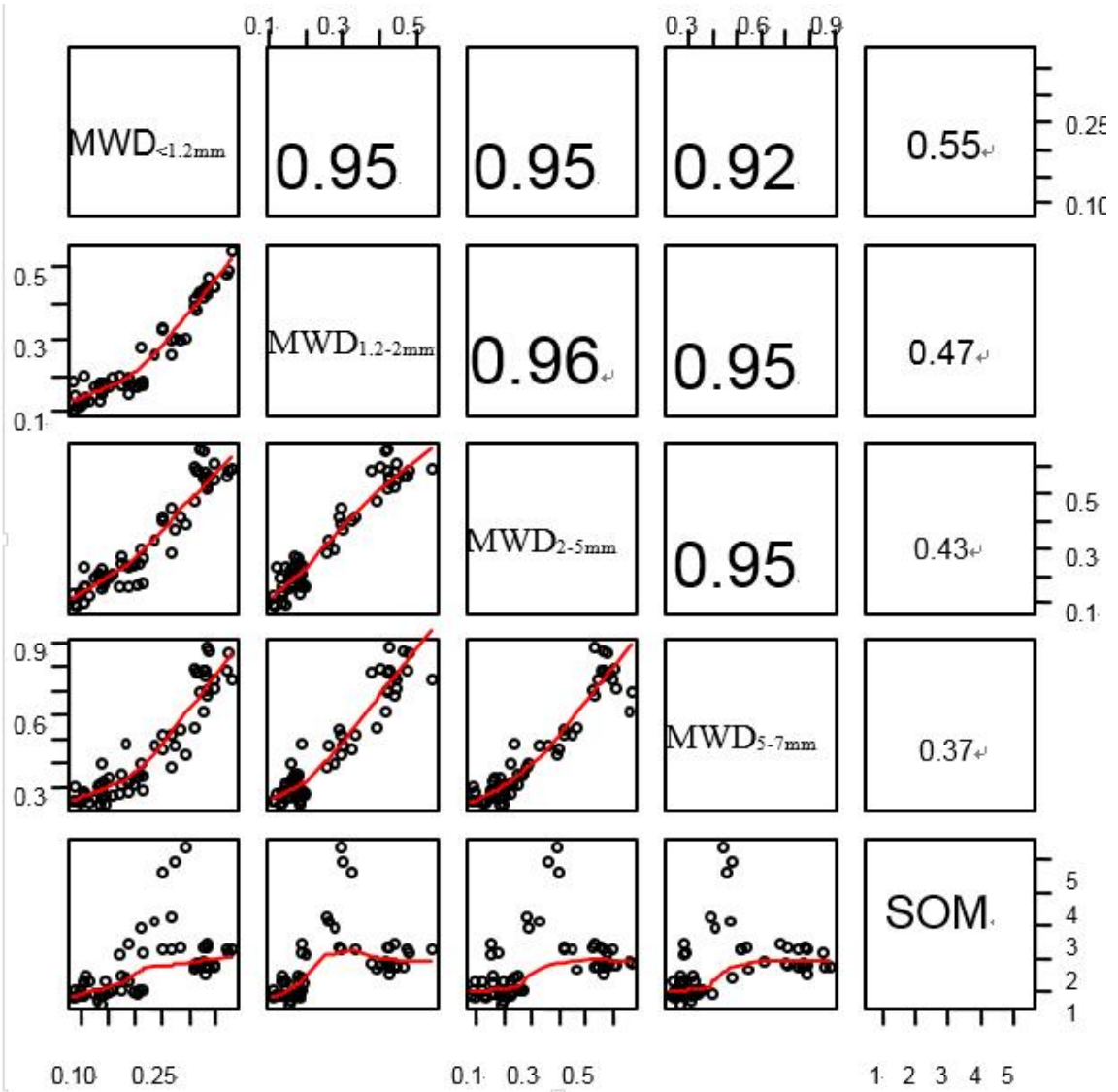




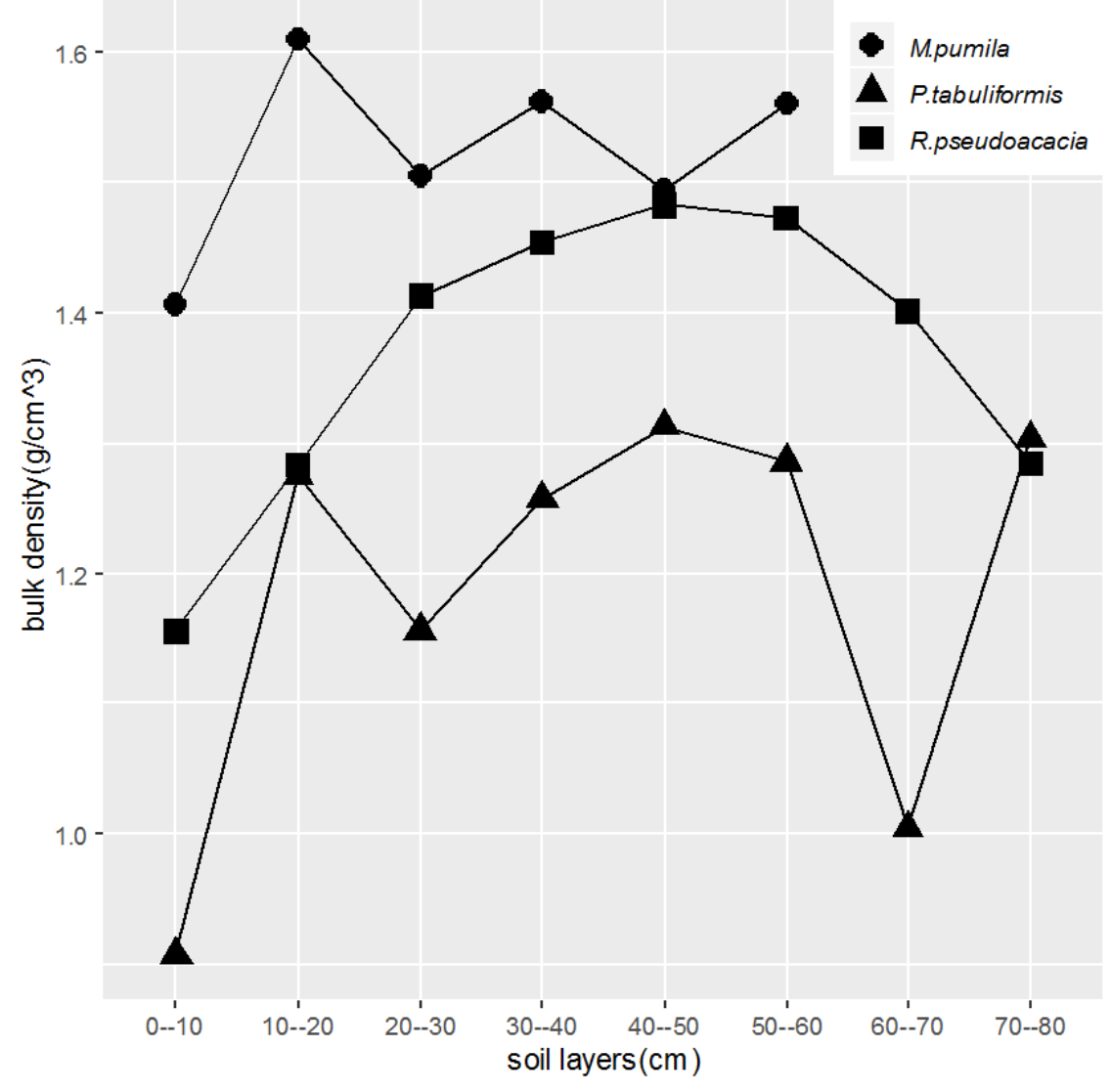



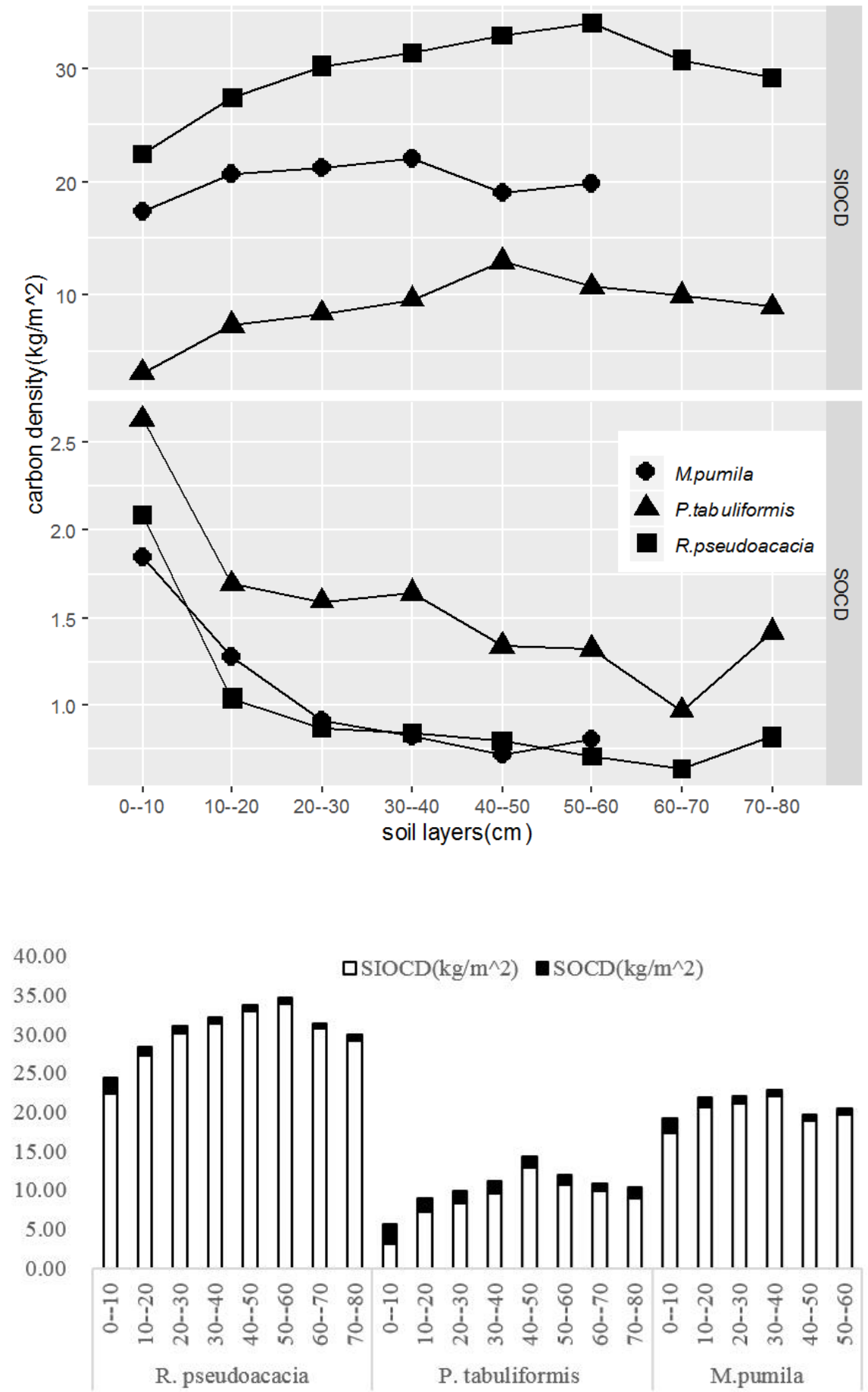


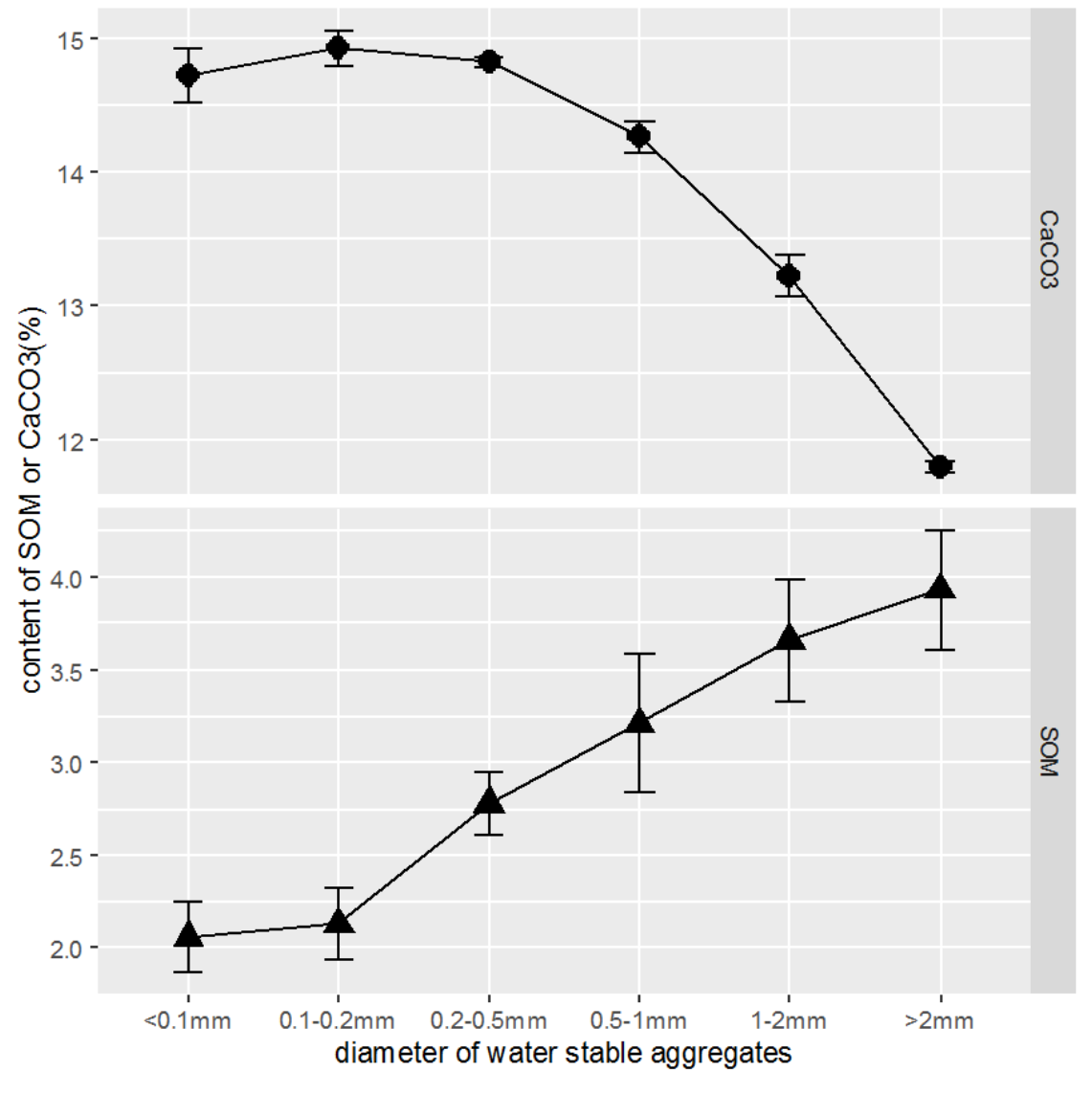

